International Economic Journal

\title{
Global Sensitivity of Neoclassical and Factor Proportions Models to Production Technology.
}

\section{Jon M. Ford \& Henry Thompson}

To cite this article: Jon M. Ford \& Henry Thompson (1997) Global Sensitivity of Neoclassical and Factor Proportions Models to Production Technology., International Economic Journal, 11:3, 61-74, DOI: $10.1080 / 10168739700000019$

To link to this article: https://doi.org/10.1080/10168739700000019

曲 Published online: 28 Jul 2006.

Submit your article to this journal $๘$

山 Article views: 15 


\title{
GLOBAL SENSITIVITY OF NEOCLASSICAL AND FACTOR PROPORTIONS MODELS TO PRODUCTION TECHNOLOGY
}

\author{
JON M. FORD \\ University of Texas-Arlington \\ HENRY THOMPSON* \\ Auburn University
}

\begin{abstract}
This paper pictures the global influence of various patterns of returns to scale in the general equilibrium model of production with two factors and two goods. Constant, increasing, and decreasing returns to scale at the sectoral level are explicitly specified. The changing slope and curvature of contract curves, isoquants, production frontiers, and relative price lines are examined under various Cobb-Douglas and exponential production functions. Fundamental properties of neoclassical and factor proportions theory are thus illustrated. [D50, F11]
\end{abstract}

\section{INTRODUCTION}

This paper explores the global sensitivity of contract curves, isoquants, production possibility frontiers, and relative price lines to various returns to scale. These curves are an important part of the general equilibrium economics of production, and their slope and curvature reflect the direction and strength of global adjustment in outputs and factor prices to underlying changes in the prices of outputs.

Qualitative comparative static analysis, exemplified by Jones (1968), is concerned with the direction of local adjustment around an equilibrium. Global properties of these important theoretical models, however, remain largely unexplored. The range and responsiveness of outputs and factor prices to exogenous changes in the prices of goods are potentially as important as the direction of local changes.

Samuelson (1971) argues that the production possibility frontier is less concave in the specific factors model than usually perceived. This paper shows the frontier to be nearly linear in the two factor model when there are constant returns to scale and factor intensities are not widely different across goods. The implication is that outputs are extremely sensitive to price changes. In a small open economy, changes in world prices or the level of protection would thus have large output effects.

Variable returns to scale in the factor proportions model of production and trade

*Thanks go to T. Randolf Beard, Joseph P. Wesson, and C. Robert Taylor for discussions on critical points as this paper developed. A referee and an editor of this journal provided suggestions which clarified some critical points and improved the exposition. 
have been explored by Kemp (1964), Minabe (1966), Jones (1968), Herberg and Kemp (1969), Panagariya (1980,1983), and others, and the vast literature is reviewed by Helpman (1984). The focus has been on the local conditions under which the Stolper-Samuelson, Rybczynski, and factor price equalization theorems hold. The present paper pictures the related global properties of the two factor, two good model with various combinations of returns to scale across sectors.

This paper utilizes the general equilibrium model of production with two factors and two goods. Each sector is made up of numerous identical firms. Returns to scale are constant at the firm level, and economies or diseconomies are introduced by a scale effect. The model allows entry and exit, but does not solve for the number of firms. Cobb-Douglas and exponential production functions are specified. Models with various degrees of constant, increasing, and decreasing returns to scale in either sector are examined. Changes in the technological parameters of the exponential production functions lead to pictured shifts in the slope and curvature of the various curves.

Convex production possibility frontiers due to increasing returns to scale are derived. Increasing returns in one sector in combination with decreasing returns in the other sector lead to frontiers which are partly convex and partly concave, giving rise to a potential dual general equilibrium in which the relative price line, which maps relative prices to relative factor prices, is not a singular mapping.

Elasticities of relative factor prices and output substitution with respect to relative prices of goods are also reported. There is a good deal of variation across technologies in the global responsiveness of factor prices and outputs to exogenous changes in the prices of goods.

\section{METHOD OF SOLUTION}

The exponential production function in either sector is specified as

$$
\begin{aligned}
& x_{1}=\left(I-v_{12}\right)^{\alpha}\left(I-v_{22}\right)^{\beta} \\
& x_{2}=v_{12} \gamma_{v_{22}} \delta .
\end{aligned}
$$

Outputs are $x_{j}, j=1,2$. The total input of factor $i(i=1,2)$ in the production of good $j$ is written $v_{i j}$. Note that the total endowment of each factor has been standardized to $l: v_{i l}+v_{i 2}=l, i=l, 2$.

Technological parameters are given by the transposed technology vector $t=(\alpha \beta \gamma$ $\delta$ ) and are chosen to depict various degrees of constant, increasing, and decreasing returns to scale. If $\alpha+\beta$ or $\gamma+\delta$ equals one, that sector's production function is Cobb-Douglas, constant returns to scale (CRS).

At the level of the firm, CRS is maintained in order to keep the firm's profit function bounded. A scale effect $g_{j}\left(x_{j}\right)$ is introduced as in Kemp (1964) to create 
variable returns at the industry level,

$$
x_{j}=v_{l j}^{a} v_{2 j}^{b}=n_{j} g_{j}\left(x_{j}\right) \phi_{l j}^{c} \phi_{2 j}^{d},
$$

where $n_{j}$ is the number of firms producing good $j, \phi_{i j}$ is the input of factor $i$ in one of the $n$ identical firms, $n_{j} \phi_{i j}=v_{i j}, a+b=1$, and $c+d=1$. Economies and diseconomies are external to the firm but internal to the industry, as discussed by Kemp and Negishi (1970).

It is curious that the scale or externality effect in (3) is

$$
g_{j}\left(x_{j}\right)=v_{l j}^{a-c} v_{2 j}^{b-d}
$$

an exponential function itself. It follows that

$$
d g_{j} / d x_{j}=\Sigma_{i}\left(d g_{j} / d v_{i j}\right) /\left(d x_{j} / d v_{i j}\right)
$$

which must have the same sign as $a(b-d)+b(a-c)$.

This model does not solve for the number of firms in sector $j, n_{j}$. Variable returns are thus placed on the same theoretical footing as constant returns. The number of identical firms, $n_{j}$, is neutral in its effect on the general equilibrium. A different $n_{j}$ would imply a different level of inputs $\phi_{i j}$, consistent with the same total sectoral output, for the typical firm. With free entry and exit, the number of firms $n_{j}$ and inputs at the level of the firm $\phi_{i j}$ are constrained to adjust so profit equals zero.

A specified production function in (1) and (2) leads to a corresponding set of isoquants, the contract curve (CC), production possibility frontier (PPF), and relative price line (RPL).

Optimal output can be derived by maximizing the Lagrangian function:

$$
L=v_{12}^{\gamma} v_{22}^{\delta}+\lambda\left[x_{1}-\left(1-v_{12}\right)^{\alpha}\left(1-v_{22}\right)^{\beta}\right]
$$

First order conditions are

$$
\partial L / \partial v_{12}=\psi_{12}^{\gamma-1} v_{22}^{\delta}+\alpha \lambda\left(1-v_{12}\right)^{\alpha-1}\left(1-v_{22}\right)^{\beta}=0
$$




$$
\begin{aligned}
& \partial L / \partial v_{22}=\delta v_{12}^{\gamma} v_{22}^{\delta-1}+\beta \lambda\left(l-v_{12}\right)^{\alpha}\left(l-v_{22}\right)^{\beta-1}=0 \\
& \partial L / \partial \lambda=x_{1}-\left(1-v_{12}\right)^{\alpha}\left(1-v_{22}\right)^{\beta}=0 .
\end{aligned}
$$

Because of the exponents, there is no closed solution. Instead, $v_{22}$ is discretely varied between zero and one to derive plots of the various curves.

From (7),

$$
\lambda=-p_{1} / p_{2}=-\left(\gamma x_{2} / v_{12}\right) /\left[\alpha x_{1} /\left(1-v_{12}\right)\right]
$$

The Lagrangian multiplier $\lambda$ is thus interpreted as $d x_{2} / d x_{I}$, the slope of the PPF. For notation, $p \equiv p_{1} / p_{2}=-\lambda$. From (8) and (10),

$$
v_{12}=\left(\beta w_{22}\right) /\left[\beta \gamma_{22}+\delta \alpha\left(1-v_{22}\right)\right]
$$

The optimal $v_{12}$ can thus be found for any $v_{22}$. Then, from (9) and (11),

$$
x_{1}=\left(l-v_{22}\right)^{\beta}\left\{\left[\delta \alpha\left(l-v_{22}\right)\right] /\left[\delta \alpha\left(l-v_{22}\right)+\beta w_{22}\right]\right\}^{\alpha} .
$$

Finally, $x_{2}$ is calculated from (2).

First order conditions thus lead to expressions for the optimal $x_{1}$ in (12) and $x_{2}$ in (2) for arbitrary $v_{22}$. The marginal rate of technical substitution (MRTS) along the isoquant is the ratio of marginal products, $\left(\partial x_{j} / \partial v_{l j}\right) /\left(\partial x_{j} / \partial v_{2 j}\right)=\partial v_{2 j} / \partial v_{1 j}$. In the cost minimization, MRTS $=w_{1} / w_{2}$. The relative factor price is derived as

$$
w \equiv w_{I} / w_{2}=\partial v_{22} / \partial v_{12}
$$

For a given set of technological parameters, the various curves are plotted through 
variation in $v_{22}$. Isoquants can also be generated, but are not pictured due to space constraints. For consistency, the production of good 1 is kept intensive in factor 1 in every specification.

\section{MODELS WITH CONSTANT RETURNS TO SCALE}

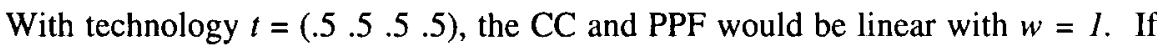
the two goods are identical in their production functions, the CC and PPF would be linear and $w$ would be uniquely determined. Consider the technology $t_{l}=\left(\begin{array}{ll}.8 & 2 \\ 2 & 2.8\end{array}\right)$. Table 1 illustrates the variational technique used to plot the various curves.

Table 1. Example of Plots with $t_{1}$

\begin{tabular}{cccccc}
\hline$v_{22}$ & $v_{12}$ & $x_{2}$ & $x_{1}$ & $p$ & $w$ \\
\hline 0.000 & 0.000 & 0.000 & 1.000 & & \\
0.100 & 0.007 & 0.059 & 0.974 & 2.166 & 3.625 \\
0.200 & 0.015 & 0.120 & 0.945 & 2.028 & 3.250 \\
0.300 & 0.026 & 0.184 & 0.912 & 1.884 & 2.875 \\
0.400 & 0.040 & 0.252 & 0.874 & 1.733 & 2.500 \\
0.500 & 0.059 & 0.326 & 0.829 & 1.572 & 2.125 \\
0.600 & 0.086 & 0.407 & 0.775 & 1.399 & 1.750 \\
0.700 & 0.127 & 0.498 & 0.705 & 1.211 & 1.375 \\
0.800 & 0.200 & 0.606 & 0.606 & 1.000 & 1.000 \\
0.900 & 0.360 & 0.749 & 0.442 & 0.754 & 0.625 \\
1.000 & 1.000 & 1.000 & 0.000 & & \\
\hline
\end{tabular}

With $t_{1}$, note that the $\mathrm{CC}$ in Figure 1 is quite convex, while the PPF in Figure 2 is much less concave. PPFs are only slightly concave under CRS, as reflected by the very limited domain of prices for the RPL in Figure 3 consistent with diversified production. If complete specialization is reached, factor prices would not adjust to further changes in the prices of goods. The RPLs in Figure 3, in other words, could be extended horizontally from either end as in Kemp (1964).

If an economy with technology $t_{l}$ moves from autarky to free trade in Figure 2, an industry would likely shut down as prices of goods adjust to international levels. Imagine an economy made up of many such industries, all with CRS and with this degree of variation across production functions. Exogenous changes in prices of goods brought about by a change in world prices or in the level of protection would have very small effects on factor prices but very large effects on outputs. Tariffs would have overwhelming effects on outputs and would likely cause unprotected sectors to shut down. 


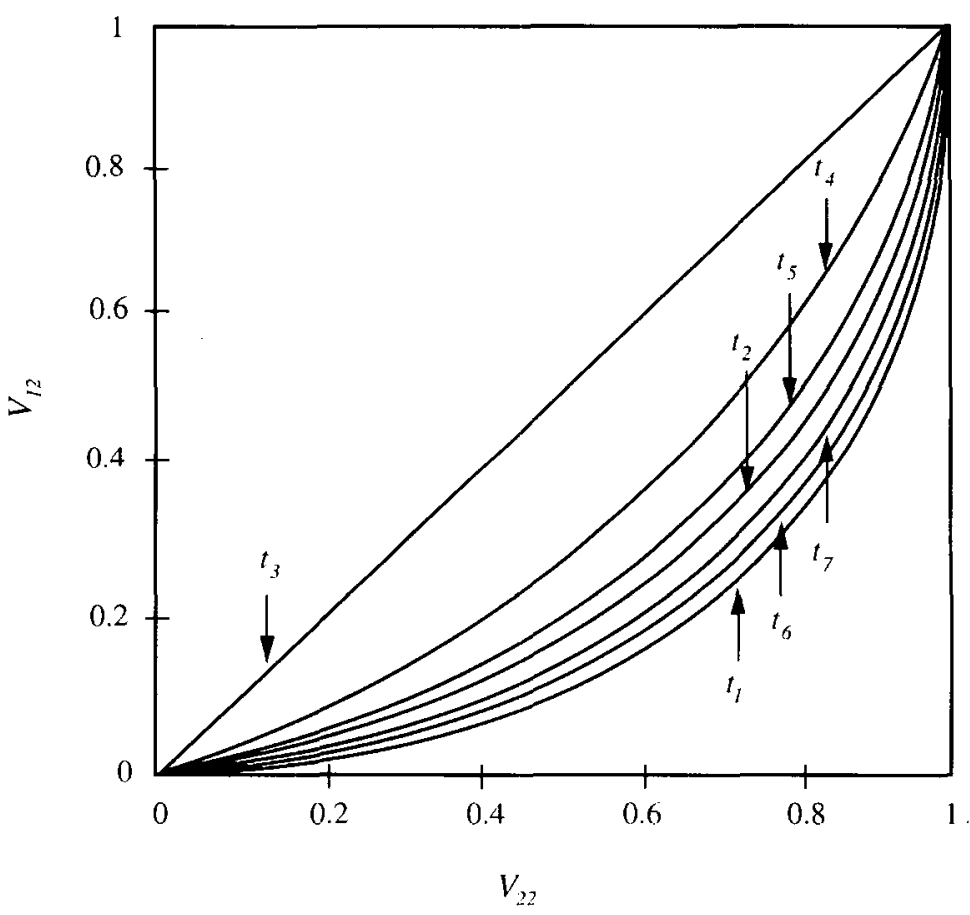

Figure 1. Contract Curves

PROPOSITION 1. With constant returns to scale, output is extremely sensitive to price changes. Complete specialization and industrial shutdown are likely outcomes of price changes.

When the symmetric difference across production functions is decreased the PPF becomes less concave and the range of the RPL is slightly decreased as the PPF becomes more elastic. In contrast, the $\mathrm{CC}$ becomes less convex.

PROPOSITION 2. With constant returns to scale and different technologies across sectors, the degree of convexity of the contract curve is much greater than the degree of concavity of the production possibility frontier.

The difference across goods is also reduced by making good 2 less intensive in factor 2. The $\mathrm{CC}$ then returns to a less concave shape. The RPL shifts back to the left, becomes steeper, and has a wider range than with the previous technologies. For most prices, this shift favors factor 1. Similar PPFs may disguise different underlying 


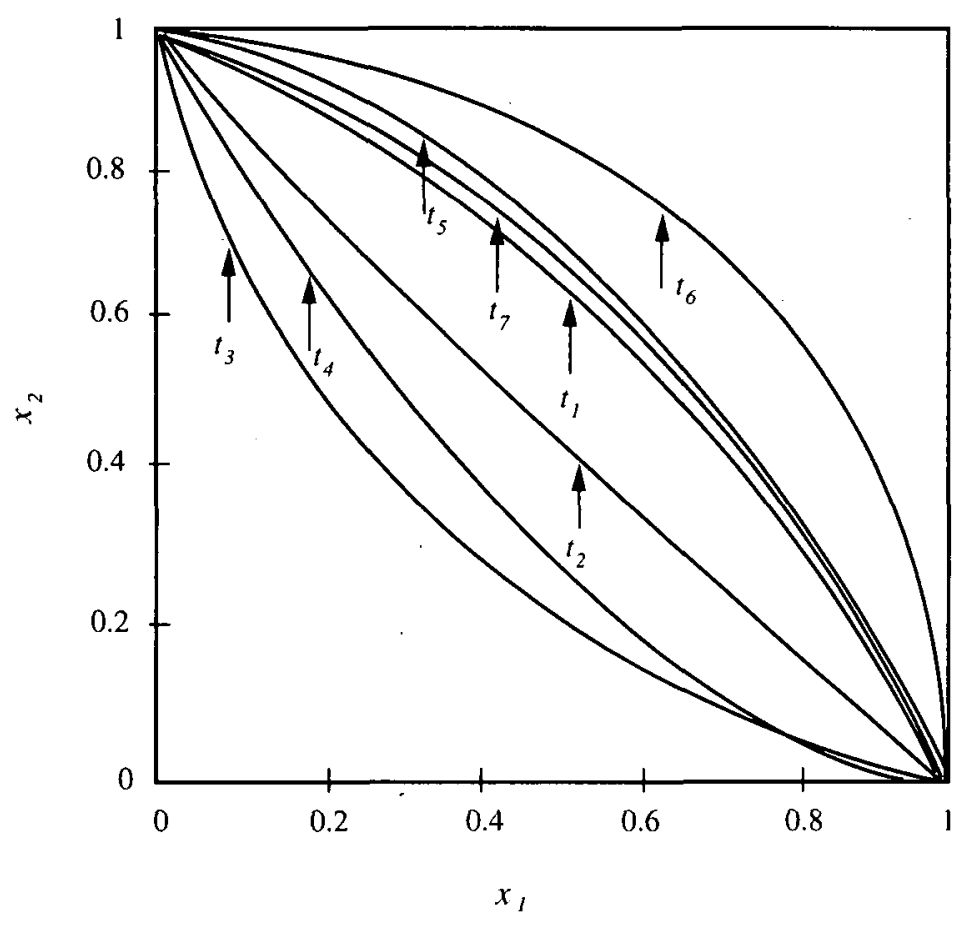

Figure 2. Production Possibility Frontiers

factor price patterns.

PROPOSITION 3. The shape of the production possibility frontier does not necessarily indicate the shape of the underlying relative price line.

In a situation of CRS with both sectors biased toward factor 1, the PPF is nearly linear, straighter even than with $t_{l}$. Isoquants in both sectors are fairly flat. The relative price of factor 1 is high, and the domain of price changes in the RPL is severely limited.

PROPOSITION 4. With constant returns to scale in both sectors, larger differences in technology across goods cause the contract curve to become more convex, the production possibility frontier to become more concave, and the positively sloped relative price line to flatten, widen in range, and become less convex. 


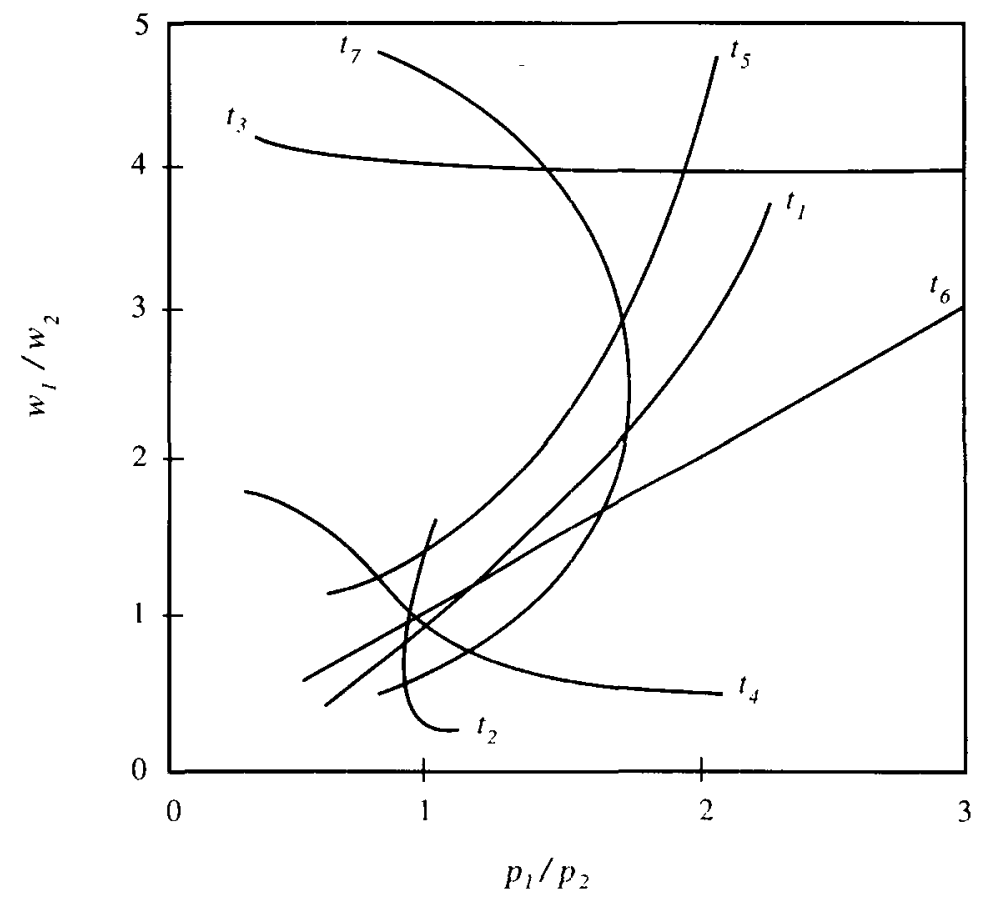

Figure 3. Relative Price Lines

\section{MODELS WITH INCREASING RETURNS TO SCALE}

When there is increasing returns to scale (IRS) in one sector with CRS in the other sector, the PPF is typically convex. An increase in the relative price of a good thus leads to a decrease in its output. Each good's long run supply curve slopes downward in the general equilibrium.

With $t=(.9 .5 .5 .5)$, there is a negatively sloped RPL (not pictured) which means that an increase in the relative price of a good decreases the price of the factor used intensively in its production. The PPF becomes less convex toward higher output of the IRS industry. The RPL becomes steeper and more convex as the relative price of the IRS good falls.

IRS in sector 1 is maintained and production of good 2 is made more intensive in factor 2 under $t_{2}=(.9 .5 .2 .8)$. The $\mathrm{CC}$ is more convex than with $t=(.9 .5 .5 .5)$. The PPF is concave toward the axis of the industry with IRS and convex toward the CRS axis. Effects of differences in factor intensity overcome effects of IRS in the concave 
region, as discussed by Kemp (1964).

PROPOSITION 5. A higher degree of increasing returns to scale causes the contract curve to become more convex and the production possibility frontier to become more concave. The negatively sloped concave relative price line widens in range and becomes less concave.

A dual equilibria is possible with $t_{2}$. If $p=1$, for instance, there are two different equilibrium points on each of the PPF, CC, and RPL. Stability analysis would introduce demand and examine stability of the equilibrium on the convex portion of the PPF, corresponding to the negatively sloped portion of the RPL. In a pure production model of a small open economy with exogenous prices, the dual equilibria is possible. At the convex equilibrium, relatively little of the good with IRS is produced. In this convexity "trap," a higher relative price for the IRS good lowers the relative return to factor 1 and pushes both factors into the large CRS sector.

PROPOSITION 6. Increasing returns to scale in one sector cause a convex production possibility frontier unless the factor intensity difference is large.

Both sectors use a similar high ratio of factor 1 to factor 2 and the factor intensity difference between sectors is reduced with $t_{3}=(2.1 .5 .8 .2)$. With similar input ratios, the CC is nearly linear and the isoquants both biased toward factor 1 and only slightly convex. The PPF is extremely convex toward the axis of the CRS industry. The RPL is nearly linear, indicating a relatively high return to factor 1 across a wide domain of prices.

In a model with IRS in both sectors and production in both sectors biased toward factor 1 , the CC is straight, the PPF convex, and the negatively sloped RPL almost straight. If the IRS production technologies were identical across sectors, the $\mathrm{CC}$ and PPF would be linear. A large intensity difference across sectors is pictured with $t_{4}=$ $(9.5 .5 .8)$. The result is a moderately convex $\mathrm{CC}$, while the PPF remains convex. Similarity of the PPFs occurs with IRS in both sectors, hiding underlying differences in the CCs and RPLs as the degree of IRS varies.

\section{MODELS WITH DECREASING RETURNS TO SCALE}

Consider now the effects of DRS in one sector. With $t_{5}=(.5 .1 .5 .5)$, the CC and PPF look much like those typically drawn and the RPL extends over a fairly wide range of relative prices. The PPF becomes less concave as output in the CRS industry increases. Compare $t_{5}$ with $t_{2}$ to see the effects of a move toward DRS in one sector.

PROPOSITION 7. As returns to scale fall in the production of one good, the contract 
curve becomes more convex, the production possibility frontier becomes more concave, and the positively sloped relative price line becomes steeper, wider in range, and less convex.

The factor intensity difference is enlarged by making production in sector 2 more intensive in factor 2. The CC then becomes more convex and the PPF more concave. The domain of the RPL widens as the RPL flattens and becomes less convex.

In a situation with both sectors biased toward factor 1 and a small factor intensity difference, the $\mathrm{CC}$ is nearly straight. A high return to factor 1 is suggested by flat isoquants. The PPF is less concave than with $t_{5}$. The RPL also indicates a very high relative return to factor 1 .

A large factor intensity difference across sectors with DRS in both sectors is pictured with $t_{6}=\left(\begin{array}{ll}5 & .1 \\ 2 & 2.5\end{array}\right)$. Contrast $t_{6}$ with $t_{5}$ which has DRS in only one sector. The $\mathrm{CC}$ has become more convex, and the PPF more concave. The RPL has widened its domain, switched from convex to concave, and shifted to indicate a higher relative return to factor 2 .

With $t=\left(\begin{array}{lll}5 & .1 & .5\end{array} .2\right)$, the increased intensity of factor 1 in the production of good 2 would cause the RPL to rise and become concave. The $\mathrm{CC}$ would be less convex, while the PPF remains roughly the same. Again, if the DRS technology were identical across sectors, the CC and PPF would be linear.

\section{DECREASING RETURNS MIXED WITH INCREASING RETURNS}

The last technology reports a model with DRS in one sector and IRS in the other. A large difference in factor intensity is introduced with $t_{7}=\left(\begin{array}{lll}.5 & 1 & 1 \\ .5 & .9\end{array}\right)$.

The PPF is convex toward the axis of the IRS industry, but remains concave toward the axis of the DRS industry. As the difference between sectors increases, the PPF and RPL exhibit greater curvature. The RPL bends back on itself. A given relative price $p$ of the two goods may thus be consistent with two relative factor prices $w$ and two points on each of the CC, PPF, and RPL.

This potential dual equilibrium means that first order conditions alone do not guarantee an optimal outcome. Projecting to models with many goods, the lesson is that a small open economy facing exogenous prices may end up with different sets of consistent outputs and factor prices. Global analysis becomes especially relevant. In a closed economy with domestic demand, imposing "stability conditions" rules out convex portions of the PPF.

PROPOSITION 8. With decreasing returns to scale in one sector and increasing returns to scale in the other, the production possibility frontier is concave toward higher output in the decreasing returns sector and convex toward higher output in the increasing returns sector. The relative price line bends back on itself, and the mapping from the prices of goods to factor prices is not univalent. 


\section{FACTOR PRICE AND OUTPUT ELASTICITIES}

This section specifies general equilibrium elasticities in order to gain a better understanding of the underlying adjustment processes. Table 2 reports elasticities of relative factor prices with respect to the relative prices of goods,

$$
\varepsilon_{w p} \equiv d \ln w / d \ln p=\% \Delta w / \% \Delta p
$$

and elasticities of output substitution

$$
\varepsilon_{x p} \equiv d \ln x / d \ln p=\% \Delta x / \% \Delta p
$$

where $x \equiv x_{l} / x_{2}, w \equiv w_{1} / w_{2}$, and $p \equiv p_{1} / p_{2}$. Arc elasticities at $p=1$ are calculated across the smallest price increase in the simulations. Note that technologies other than those pictured are presented for contrast.

For instance, $p$ is varied under $t_{l}$ from 1 to 1.211 in Table 1 to derive $\varepsilon_{w p}=1.78$ and $\varepsilon_{x p}=1.98$ in Table 2 . Arc elasticities would vary for different levels and discrete changes of $p$, but inspection of the figures verifies the results of this section.

With CRS in both sectors, there is very high but sharply decreasing factor price elasticity as the difference across production functions increases. The RPL flattens as the $\mathrm{CC}$ becomes more convex. The factor price elasticities and the output elasticities are both high in $t_{1}$.

PROPOSITION 9. With constant returns to scale in both sectors, factor price elasticities and output elasticities are both highly elastic for a wide range of relative prices.

With IRS in one sector, the negatively sloped RPL is inelastic. A higher $p$ causes the relative output of good 1 to fall along the $\mathrm{CC}$ and the relative price of factor 1 to fall. In $t_{2}$, the dual equilibrium gives rise to two sets of elasticities. In $t=(2.1 .5 .8$ .2 ), the factor price elasticity is very small, but the output elasticity maintains a high magnitude.

With IRS in both sectors, factor price elasticities are negative but very inelastic when factor intensity differences are small. With a large factor intensity difference, the negative factor price elasticity becomes larger. Output elasticities are negative and remain large in magnitude.

PROPOSITION 10. Increasing returns to scale in both sectors implies negative and very elastic output elasticities, while factor price elasticities are negative but much smaller in magnitude for a range of relative prices. Dual stable equilibria may exist. 
Table 2. Factor Price and Output Elasticities

\begin{tabular}{|c|c|c|c|c|c|c|c|c|}
\hline & & & & & & $\varepsilon_{w p}$ & & $\varepsilon_{x p}$ \\
\hline \multirow{5}{*}{ CRS-CRS } & \multirow{5}{*}{$t_{l}$} & .6 & .4 & .4 & .6 & 5.00 & & 23.77 \\
\hline & & .7 & .3 & .3 & .7 & 2.99 & & 5.21 \\
\hline & & .8 & .2 & .2 & .8 & 1.78 & & 1.98 \\
\hline & & .8 & .2 & .5 & .5 & 3.33 & & 8.97 \\
\hline & & .8 & .2 & .7 & .3 & 10.00 & & 73.25 \\
\hline \multirow[t]{3}{*}{ IRS-CRS } & & .9 & .5 & .5 & .5 & -0.59 & & -5.26 \\
\hline & $t_{2}$ & .9 & .5 & .2 & .8 & -2.28 & 4.81 & $-7.12 \quad 18.56$ \\
\hline & $t_{3}$ & 2.1 & .5 & .8 & .2 & -0.02 & & -2.34 \\
\hline \multirow[t]{2}{*}{ IRS-IRS } & & .9 & .5 & .8 & .5 & -0.08 & & -3.75 \\
\hline & $t_{4}$ & .9 & .5 & .5 & .8 & -0.98 & & -4.70 \\
\hline \multirow[t]{3}{*}{ DRS-CRS } & $t_{5}$ & .5 & .1 & .5 & .5 & 0.91 & & 1.89 \\
\hline & & .5 & .1 & .2 & .8 & 1.05 & & 0.89 \\
\hline & & .5 & .1 & .8 & .2 & 0.15 & & 2.45 \\
\hline \multirow[t]{2}{*}{ DRS-DRS } & & .5 & .1 & .5 & .2 & 0.43 & & 1.69 \\
\hline & $t_{6}$ & .5 & .1 & .2 & .5 & 0.97 & & 0.84 \\
\hline \multirow[t]{2}{*}{ DRS-IRS } & & .5 & .1 & .9 & .5 & -0.40 & 0.46 & $-4.24 \quad 2.48$ \\
\hline & $t_{7}$ & .5 & .1 & .5 & .9 & -0.25 & 1.14 & $-3.41 \quad 1.98$ \\
\hline
\end{tabular}

With DRS in one sector, factor price elasticities are positive. The three sets of elasticities in this group reflect the curvature of the RPLs and PPFs. Factor price elasticities are typically inelastic, and output elasticities are relatively small. A larger factor price elasticity, created by larger differences in factor intensity across sectors, leads to smaller output elasticities with DRS in one sector.

With DRS in both sectors, the factor price elasticities in $t_{6}$ are positive, inelastic, and higher with a larger factor intensity difference. Again, a larger factor price elasticity means a smaller output elasticity. Compared with the CRS group, elasticities in the DRS group are much less elastic.

In the mixed DRS-IRS group, the sign of the factor price elasticities depends on the economy's position along its PPF. A relative price of 1 is consistent with two points on the PPF and two points on the RPL. The factor price elasticity is positive where the PPF is concave, and negative where it is convex. In the concave region of the PPF, increasing the difference in returns to scale across sectors causes the factor price elasticity to become larger and the output elasticity to become smaller. The 
opposite is true (in absolute value) when the PPF is convex.

PROPOSITION 11. With exponential production functions, outputs are generally sensitive to changes in the prices of goods. Output elasticities, in other words, are generally elastic. Factor prices are generally less sensitive to changes in the prices of goods. Decreasing returns to scale has a moderating effect on both factor price elasticities and output elasticities.

\section{CONCLUSION}

This paper relates different exponential production technologies to the contract curve, production possibilities frontier, and relative price line in the general equilibrium model of production with two factors and two goods. Depending on the underlying technologies, exogenous changes in the relative prices of goods have different global effects on outputs and factor prices.

Underlying adjustment in factor prices to changes in the prices of goods varies significantly with technology. Elasticities of relative factor prices with respect to the relative prices of goods are elastic under constant returns to scale. Output elasticities are also typically elastic.

Decreasing returns to scale at the sectoral level have a moderating effect on the size of these elasticities. Casual empiricism suggests that factor prices and outputs are not outrageously sensitive to changes in the prices of goods. Decreasing returns to scale, however, are often dismissed in theoretical investigations, while increasing returns receive more attention.

This line of research can be directly extended to include many goods and factors of production. Models with three factors or three goods can be graphed. Different functional forms (constant elasticity of substitution, translog, and so on) can also be analyzed. In applied analysis, estimated production functions can be pictured.

This type of global analysis offers insight into the properties of fundamental general equilibrium models of production. It is worth emphasizing that contract curves as typically drawn with constant returns to scale are consistent with nearly linear production possibility frontiers. Production possibility frontiers as typically drawn imply radically convex contract curves.

\section{REFERENCES}

Helpman, Elhanan, "Increasing Returns, Imperfect Markets, and Trade Theory," in R.

W. Jones and P. B. Kenen, eds., Handbook of International Economics, Amsterdam: North Holland, 1984.

Herberg, Horst, and Kemp, Murray, "Some Implications of Variable Returns to Scale," Canadian Journal of Economics, August 1969, 403-415.

Jones, Ron, "Variable Returns to Scale in General Equilibrium Theory," International

Economic Review, October 1968, 261-272. 
Kemp, Murray, The Pure Theory of International Trade, Englewood Cliffs: PrenticeHall, 1964.

Kemp, Murray, and Negishi, Takashi, "Variable Returns to Scale, Commodity Taxes, Factor Market Distortions, and Their Implications for Trade Gains," Swedish Journal of Economics, January 1970, 1-11.

Minabe, Nobuo, "The Stolper-Samuelson Theorem Under Conditions of Variable Returns to Scale," Oxford Economic Papers, July 1966, 204-212.

Panagariya, Arvind, "Variable Returns to Scale in General Equilibrium Theory Once Again," Journal of International Economics, November 1980, 499-526.

, "Variable Returns to Scale and the Heckscher-Ohlin and Factor-Price-

Equalization Theorems," Weltwirtschaftliches Archiv, April 1983, 259-279.

Samuelson, Paul, "Ohlin was Right," Swedish Journal of Economics, December 1971, 365-384.

Mailing Address: Professor Jon M. Ford, Department of Economics, Box 19479, University of Texas-Arlington, Arlington, TX 76019, U.S.A. Tel: 817-272-3062, Fax: 817-272-3145,e-mail: fleiss@albert.uta.edu

Mailing Address: Professor Henry Thompson, Economics Department, College of Business, Auburn University, AL 36849, U.S.A. Tel: 334-844-2910, Fax: 4615, e-mail: hthompsn@business.auburn.edu 